\title{
O desempenho recente dos principais indicadores da economia brasileira
}

\section{Introdução}

Lucas Lautert Dezordi ${ }^{*}$ Guilherme R. S. Souza e Silva **

Esta seção do boletim Economia \& Tecnologia irá discutir cinco pontos básicos. Inicialmente, pretende-se apresentar o desempenho recente dos principais índices da inflação brasileira e suas perspectivas. Em seguida, uma análise da atividade produtiva a nível agregado, do comércio internacional e do mercado de trabalho. E, por último, uma visão da condução da política monetária será apresentada.

As previsões econômicas fornecidas foram coletadas a partir dos dados disponibilizados pelo Banco Central do Brasil em seu Departamento Gerin (GerênciaExecutiva de Relacionamento com Investidores). A Gerin foi criada em abril de 1999, como parte do arcabouço do regime monetário de metas para a inflação. Seu objetivo é monitorar a evolução do consenso de mercado para as principais variáveis macroeconômicas, de forma a gerar subsídios para a implementação da política monetária. Atualmente, a pesquisa acompanha as expectativas de mercado para diferentes índices de preços, crescimento do PIB e da produção industrial, taxa de câmbio, taxa Selic, variáveis fiscais e indicadores do setor externo?.

\section{Inflação Atual e Perspectivas}

Os dados recentes da inflação brasileira têm demonstrado um comportamento raras vezes observado, uma grande convergência dos principais índices de preços. A tabela 1 destaca as variações mensais, acumuladas no ano de 2006 e acumuladas nos últimos 12 meses dos seguintes indicadores: Índice Geral de Preços do Mercado (IGP-M); Índice Geral de Preços - Disponibilidade Interna (IGP-DI); Índice Nacional de Custo da Construção (INCC); Índice de Preço por Atacado-Disponibilidade Interna (IPA-DI); e o Índice Nacional de Preços ao Consumidor Amplo (IPCA).

Nos últimos três meses, de acordo com a tabela 1, os principais indicadores inflacionários vêm apresentando um elevado grau de convergência. Os índices de preços com

*Professor da FAE Business School e Doutorando em Desenvolvimento Econômico pela Universidade Federal do Paraná. Endereço eletrônico: 1dezordi@,fae.edu; lucasdezordi@uol.com.br

** Mestrando em Desenvolvimento Econômico pela Universidade Federal do Paraná. Endereço eletrônico: guilherme.fdg@,uol.com.br

${ }_{9}$ Ver em especial o site: www.bcb.gov.br/expectativa. 
as maiores altas nos últimos 12 meses são o INCC e o IPA-DI, com valores de 5,05\% e 4,04\%, respectivamente. O IPCA, índice de preços oficial do regime de metas de inflação, no acumulado do ano de 2006 está em 2,65\%, isto é, abaixo da meta central para o corrente ano de 4,5\%. O IPCA apresentou nos últimos 3 meses uma certa estabilidade e no acumulado em 12 meses está registrando um valor de 3,02\%.

É importante destacar que no acumulado em 12 meses os índices de preços vêm apresentando uma convergência entre 3 a $5 \%$ ao ano. $O$ gráfico 1 ilustra bem esta convergência, descrevendo o comportamento de três índices de inflação: IGP-M; IPA-DI e IPCA entre o período de janeiro de 2004 a novembro de 2006, no acumulado em 12 meses (anualizado). Destaca-se que em 2004, 2005 e primeiro semestre de 2006 esses indicadores apresentaram variações diferentes. Contudo, com a estabilidade dos níveis de preços observase um grande grau de convergência dos indicadores.

Tabela 1. Variação percentual dos principais índices de inflação brasileira

\begin{tabular}{lccccc}
\hline $\begin{array}{c}\text { Índices de } \\
\text { Inflação }\end{array}$ & Setembro & Outubro & Novembro & $\begin{array}{c}\text { Acumulado } \\
\text { em 2006 }\end{array}$ & $\begin{array}{c}\text { Acumuado em } \\
\mathbf{1 2} \text { meses }\end{array}$ \\
\hline IGPM & $0,29 \%$ & $0,47 \%$ & $0,75 \%$ & $3,52 \%$ & $3,51 \%$ \\
IGP-DI & $0,24 \%$ & $0,81 \%$ & $0,57 \%$ & $3,53 \%$ & $3,60 \%$ \\
INCC & $0,11 \%$ & $0,21 \%$ & $0,23 \%$ & $4,66 \%$ & $5,05 \%$ \\
IPA-DI & $0,28 \%$ & $1,16 \%$ & $0,75 \%$ & $4,19 \%$ & $4,04 \%$ \\
IPCA & $0,21 \%$ & $0,33 \%$ & $0,31 \%$ & $2,65 \%$ & $3,02 \%$ \\
\hline
\end{tabular}

Fonte : Banco Central do Brasil

Gráfico 1. Desempenho anualizado dos principais índices de preços

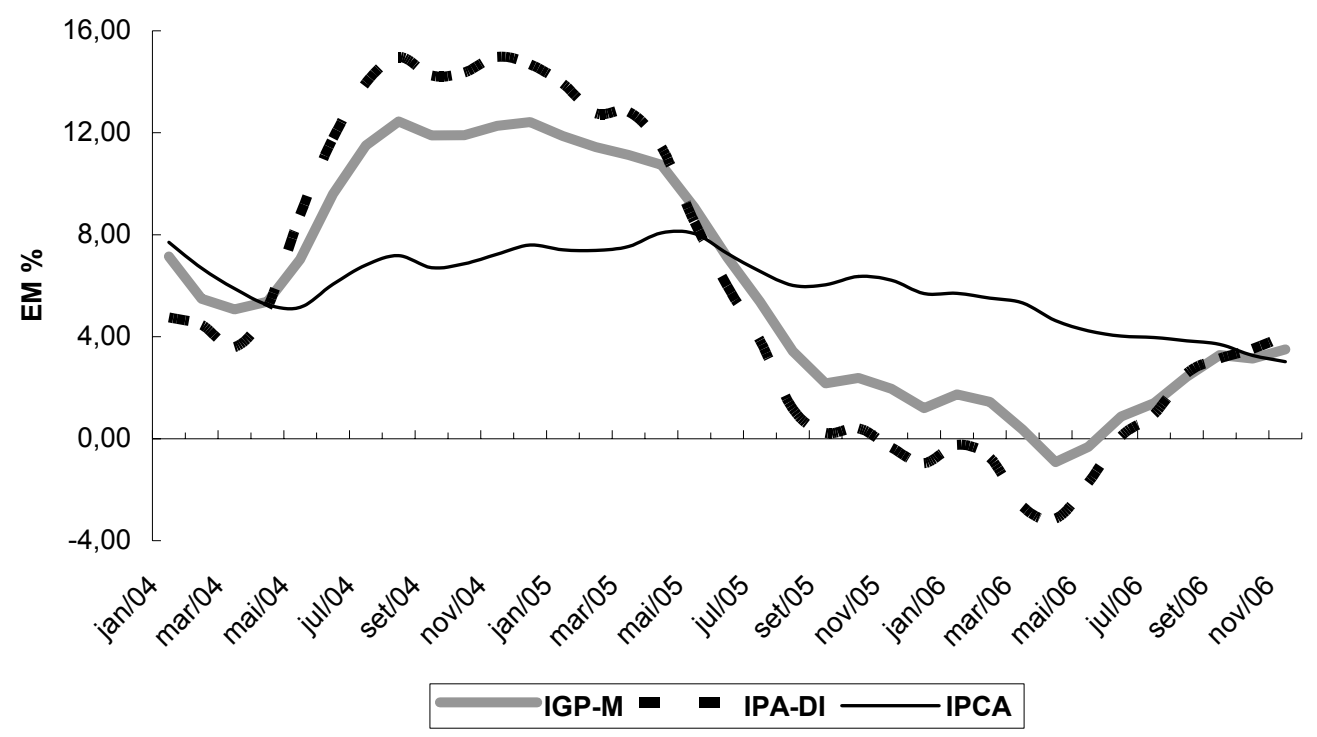

Fonte: Banco Central do Brasil 
A tabela 2 descreve as expectativas de inflação, do Gerin, para os anos de 2006 a 2010. E, mantendo a inflação baixa, o mercado espera uma maior convergências dos indicadores inflacionários. É importante ressaltar que a expectativa do IPCA para os próximos 4 anos está ancorada na meta de 4,5\% estipulada pelo Conselho Monetário Nacional (CMN).

Tabela 2. Expectativa média de inflação do mercado para os anos de 2006 a 2010

\begin{tabular}{cccccc}
\hline ANO & IGP-M & IGP-DI & INCC & IPA-DI & IPCA \\
\hline 2006 & $3,88 \%$ & $3,89 \%$ & ND & $4,58 \%$ & $3,10 \%$ \\
2007 & $4,27 \%$ & $4,24 \%$ & ND & $4,50 \%$ & $4,07 \%$ \\
2008 & $4,31 \%$ & $4,25 \%$ & ND & $4,35 \%$ & $4,26 \%$ \\
2009 & $4,36 \%$ & $4,27 \%$ & ND & $4,41 \%$ & $4,25 \%$ \\
2010 & $4,38 \%$ & $4,28 \%$ & ND & $4,56 \%$ & $4,28 \%$ \\
\hline
\end{tabular}

Fonte : Banco Central do Brasil, Gerin. Com base nas expectativas de 15/12/2006.

\section{Nível de Atividade}

À medida que nos aproximamos do final do ano de 2006, vem se confirmando a expectativa do mercado de uma baixa taxa de crescimento do PIB brasileiro para este ano. A expectativa para o crescimento do PIB, que estava em cerca de 3,5\% no início do ano, agora em dezembro está em 2,78\%, conforme mostra a tabela 3. Para 2007, as expectativas são um pouco melhores, de $3,42 \%$, porém mesmo essa taxa de crescimento ainda é considerada baixa quando comparada às taxas de outros países emergentes.

Tabela 3. Expectativas para o crescimento do PIB

\begin{tabular}{ccc}
\hline SETOR & EXPECTATIVAS DE MERCADO \\
& 2006 & 2007 \\
\hline TOTAL & $2,78 \%$ & $3,42 \%$ \\
AGROPECUÁRIA & $2,86 \%$ & $3,47 \%$ \\
SERVIÇOS & $2,53 \%$ & $3,05 \%$ \\
INDÚSTRIA & $3,08 \%$ & $4,04 \%$ \\
\hline
\end{tabular}

Fonte: Gerin - Expectativas do dia 15/12/2006

Apesar disso, o gráfico 2 mostra que no terceiro trimestre de 2006, o Brasil apresentou a maior taxa de investimento (proporção formação bruta de capital fixo/PIB) dos últimos 11 anos quando comparamos o mesmo trimestre, exceto no ano de 2004 que foi ligeiramente superior. Entretanto, é importante destacar que essa taxa de formação bruta de 
capital fixo como proporção do PIB ainda é baixa quando comparada a outros países com melhores taxas de crescimento. Considerando que em 2007 espera-se uma taxa de crescimento superior à observada em 2006, é fundamental que o Brasil consiga aumentar significativamente sua taxa de investimento.

O gráfico 3 apresenta o nível de utilização da capacidade instalada para as indústrias de bens de consumo, bens de capital, bens intermediários e uma média para a indústria. Observamos um forte aumento da utilização da capacidade da indústria de bens de capital, chegando a cerca de $84 \%$, sua utilização máxima desde o início de 2004 . Isso indica uma tendência positiva de um possível aumento nos investimentos em capital fixo. A utilização da capacidade industrial de bens de consumo, por outro lado, vinha sofrendo reduções desde o terceiro trimestre de 2005 e agora, neste último trimestre, apresentou um pequeno aumento.

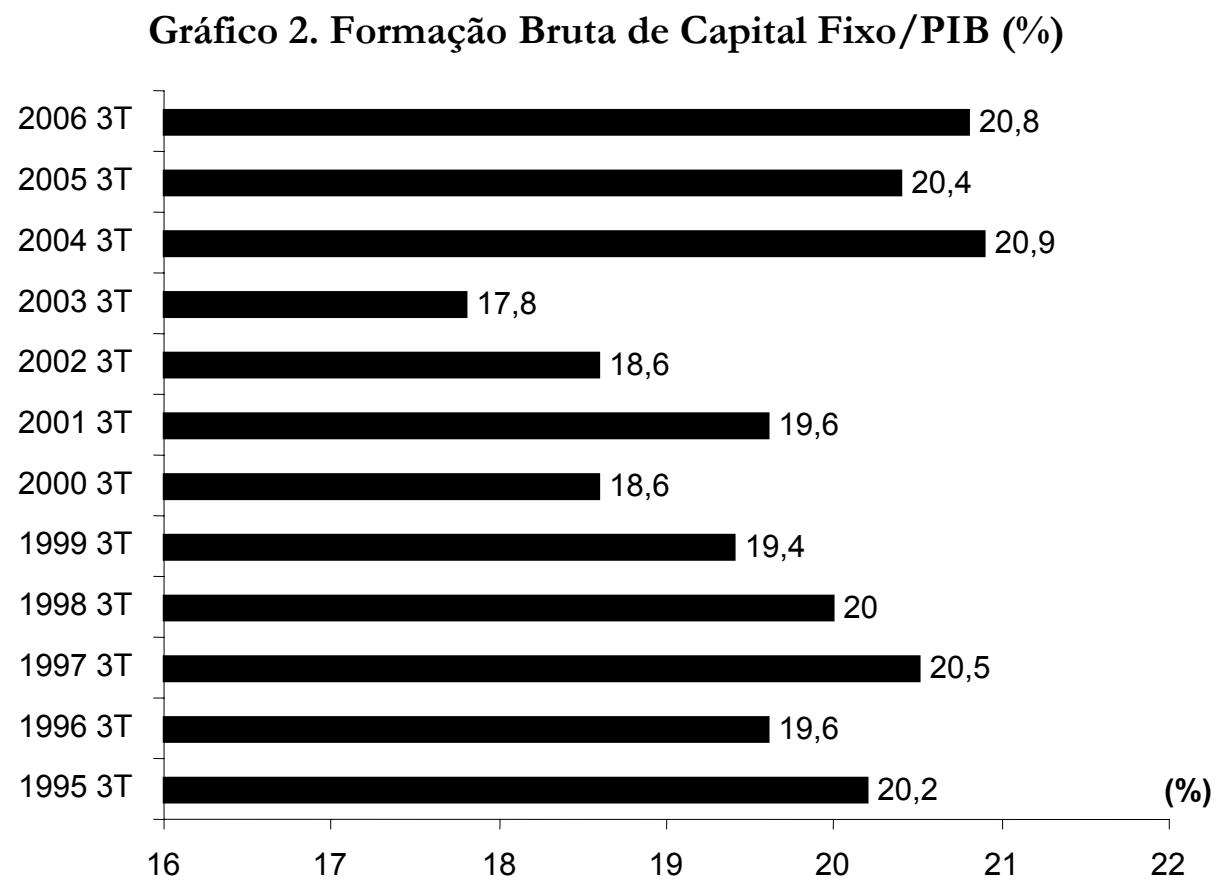

Fonte: IBGE 
Gráfico 3. Utilização da Capacidade Industrial Instalada (trimestral)

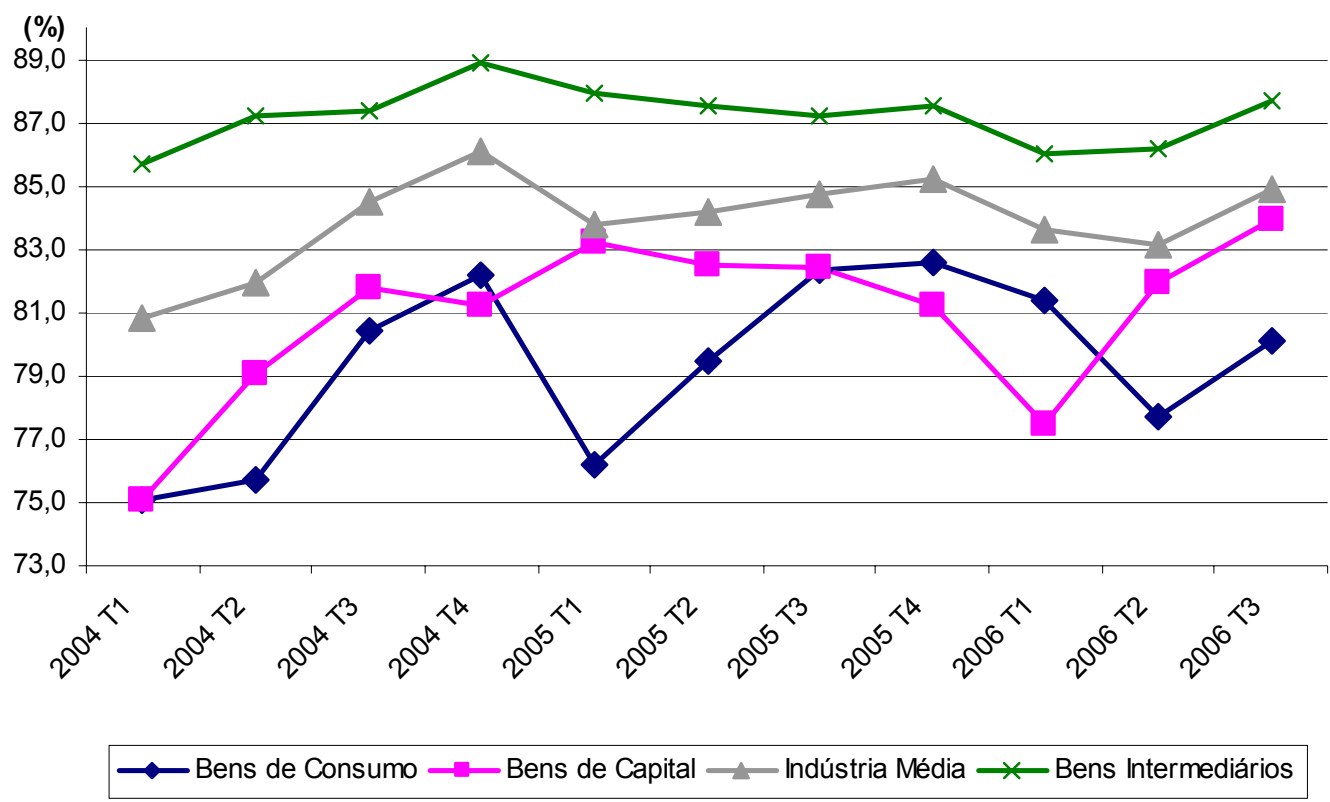

Fonte : IPEA

Finalmente, a utilização da capacidade da indústria de bens intermediários vem se mostrando mais estável, apresentando uma suave elevação no terceiro trimestre deste ano. Essa indústria apresenta os maiores níveis de utilização da capacidade em termos percentuais, variando entre $87 \%$ e $89 \%$.

O gráfico 4 apresenta o Índice Geral da Produção Industrial, considerando a média de 2002 como referência $(2002=100)$. É interessante notarmos que o índice em questão vem seguindo uma tendência constante de crescimento. Ao compararmos esses dados com os de utilização da capacidade instalada, verificamos que os últimos não apresentam tendência tão definida e comparativamente estão mais estáveis, mostrando que o aumento da produção industrial vem sendo acompanhado, em certa medida, pelo aumento da capacidade produtiva. Desta forma é perfeitamente possível que a indústria, especialmente de bens de consumo, absorva pequenos aumentos na demanda sem ultrapassar a capacidade produtiva e portanto sem pressionar o nível de preços. 


\section{Gráfico 4. Índice da Produção Industrial Geral (2002=100) - Trimestral}

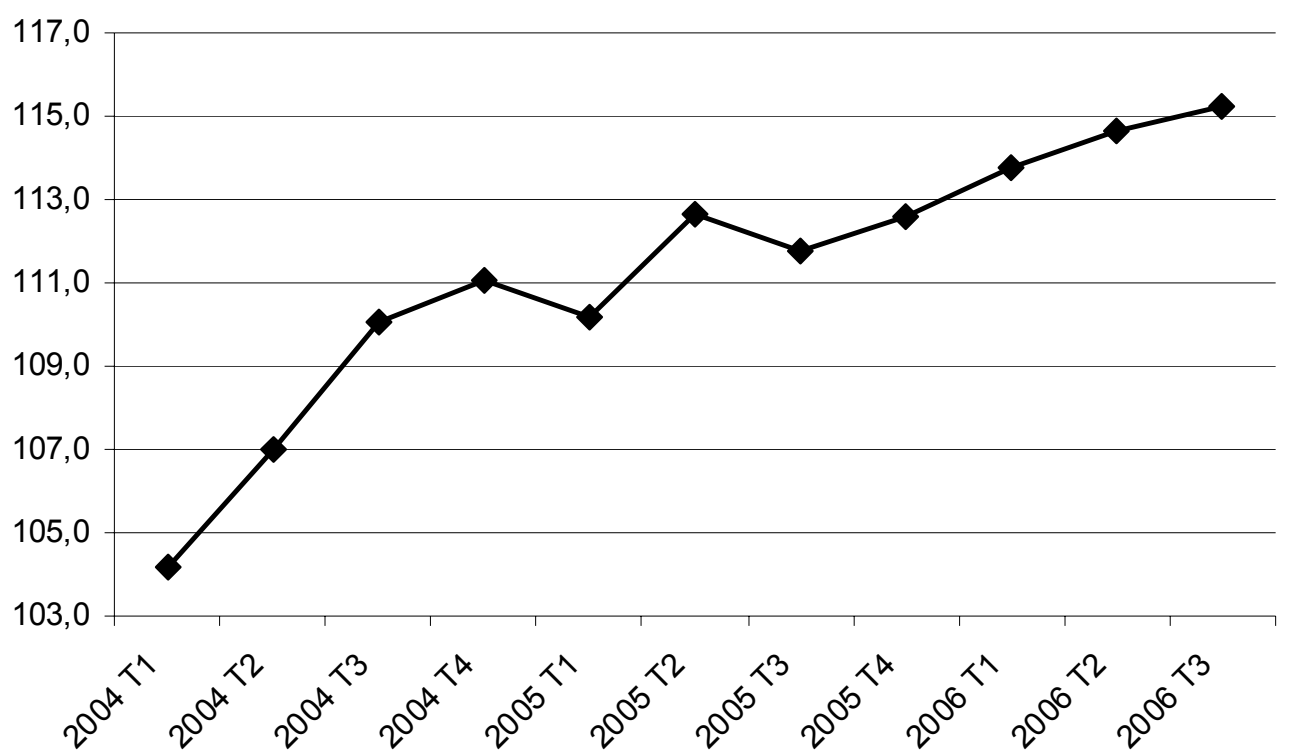

Fonte: IPEA

\section{Comércio Internacional}

O desempenho das principais variáveis do setor externo é apresentado na tabela 4 . Em outubro de 2006 o saldo da balança comercial ficou em US\$3,9 bilhões, acumulando no ano de 2006 um valor de US \$ 37,89 bilhões. As exportações e as importações já acumulam, no ano, um valor de US\$113,3 bilhões e US\$ 75,4 bilhões, respectivamente. Em doze meses, a balança comercial apresentou um superávit de US $\$ 46,3$ bilhões, as exportações um valor de US\$ 135 bilhões, as importações US\$ 88,7 bilhões. O saldo em transações correntes, em setembro, apresentou um superávit de US\$13,96 bilhões.

As expectativas de mercado para dezembro de 2006 mostram que se espera uma redução no saldo da balança comercial em relação aos números acumulados nos últimos 12 meses, indicando suave redução nas exportações e elevação nas importações, conforme destacado na tabela 4.

Em dezembro de 2006 as reservas internacionais (conceito liquidez) somaram um total de US\$ 84.723 milhões. As variáveis externas indicam um forte fluxo de comércio (exportação e importação) e uma entrada líquida de dólares, pelo saldo em transações correntes.A taxa de câmbio apreciada é conseqüência do forte resultado do setor externo, tanto pelo saldo da balança comercial como pela entrada de capitais. O gráfico 5 descreve uma queda da taxa de câmbio real de aproximadamente $21 \%$, equiparando seu valor para níveis de 1994. Isto significa que a apreciação atual do real pode ser comparada ao período do 
início do Plano Real, implementado em julho de 1994 para combater a elevada inflação, mas com uma grande vantagem: um superávit em transações correntes. Este câmbio valorizado está influenciando a queda rápida e consistente dos principais índices de inflação. Contudo, a queda significativa na taxa de câmbio nominal e real prejudica as atividades produtivas, voltadas direta ou indiretamente para as exportações.

Tabela 4. Desempenho dos Principais Indicadores Externos

\begin{tabular}{lcccc}
\hline \multicolumn{1}{c}{ SETOR EXTERNO } & EM & ACUMULADO NO & ACUMULADO & EXPECTATIVA \\
& OUTUBRO & ANO DE 2006 & NOS ÚLTIMOS 12 & PARA 2006 \\
\hline & & & & 46.317 \\
BALANÇA COMERCIAL & 3.916 & 37.890 & 135.058 & 135.310 \\
EXPORTAÇÕES (FOB) & 12.661 & 113.373 & -88.741 & 90.420 \\
IMPORTAÇÕES (FOB) & -8.745 & -75.482 & 13.960 & $-\cdots$ \\
SALDO EM TRANSAÇÕES CORRENTES & 1.526 & 11.662 & \\
\hline
\end{tabular}

Fonte : Banco Central do Brasil.

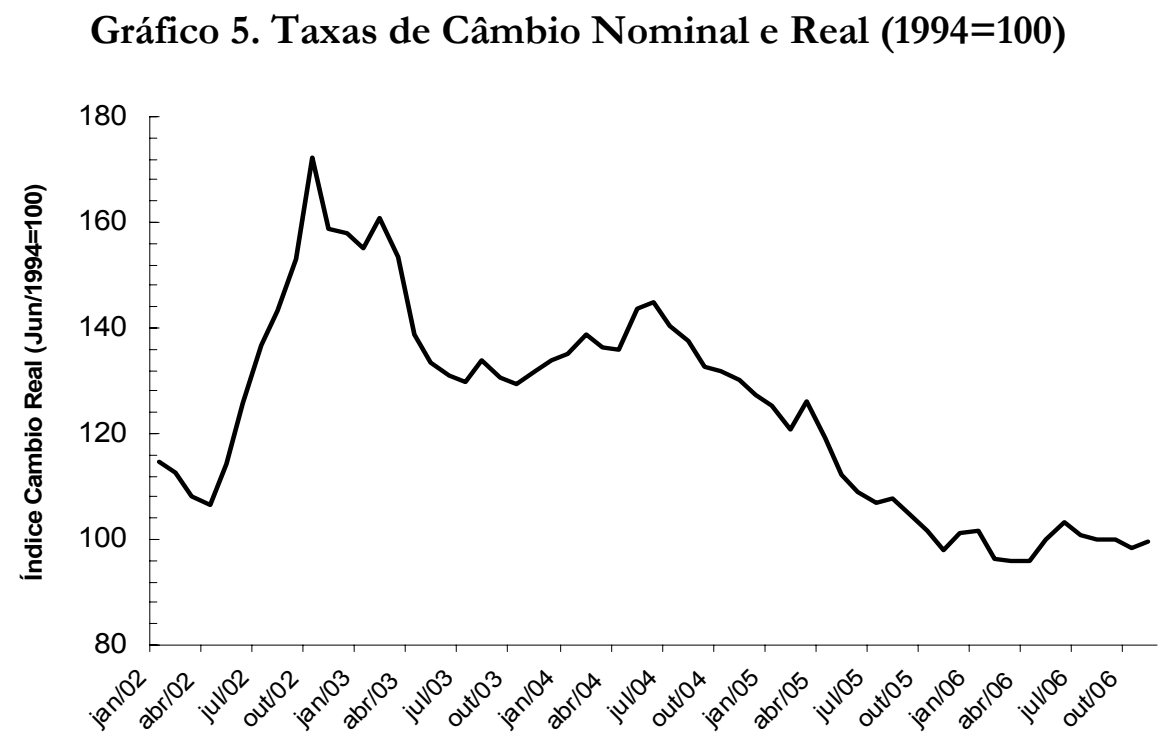

Fonte: Banco Central do Brasil

\section{Mercado de Trabalho}

A taxa de desemprego nas principais regiões metropolitanas caiu em novembro de 2006 em relação ao mesmo período do ano anterior e ao mês anterior. A taxa de desemprego encontra-se em 9,5\% da PEA (ver gráfico 6). Com isso, o rendimento médio real vem apresentando uma certa recuperação. No setor privado, o salário passou de $\mathrm{R} \$ 904,44$ para $\mathrm{R} \$ 952,90$, num período de novembro de 2005 a 2006, crescimento real de 5,35\%. Já no setor 
público, onde os salários são maiores, passaram de $\mathrm{R} \$ 1.524,54$ para $\mathrm{R} \$ 1.642,30$, no mesmo período, com crescimento real de 7,72\% (ver gráfico 7).

Gráfico 6. Taxa de desemprego nas principais regiões metropolitanas

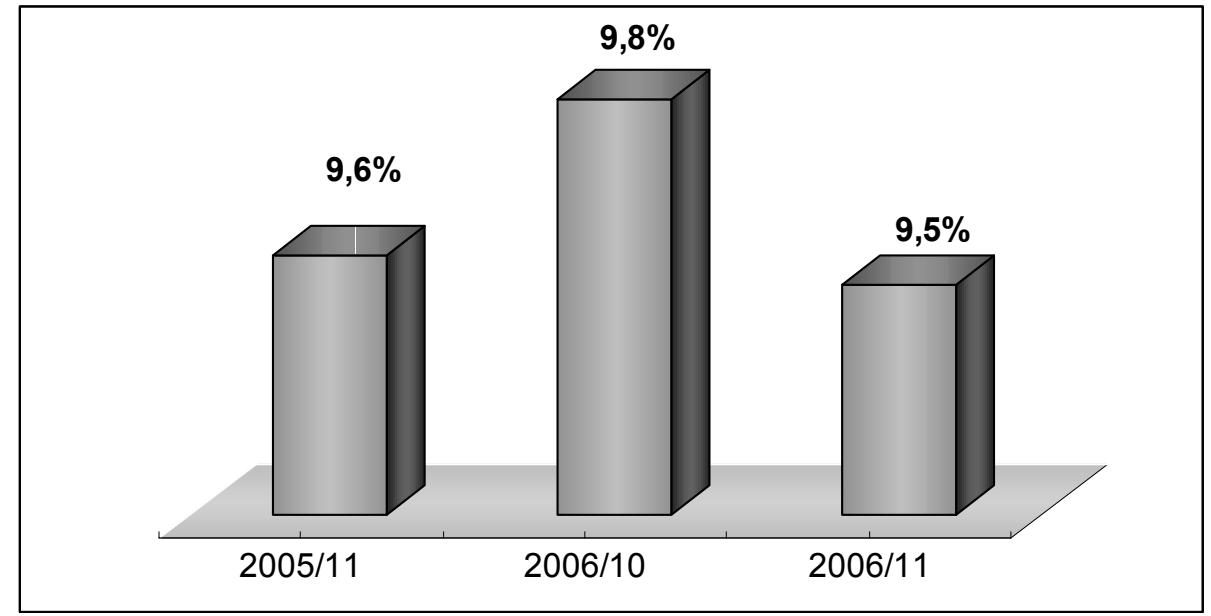

Fonte: IBGE. Região Metropolitana : RE, SAL, BH, RJ, SP E POA

Gráfico 7. Desempenho do salário médio real nas principais regiões metropolitanas, no setor privado e no setor público

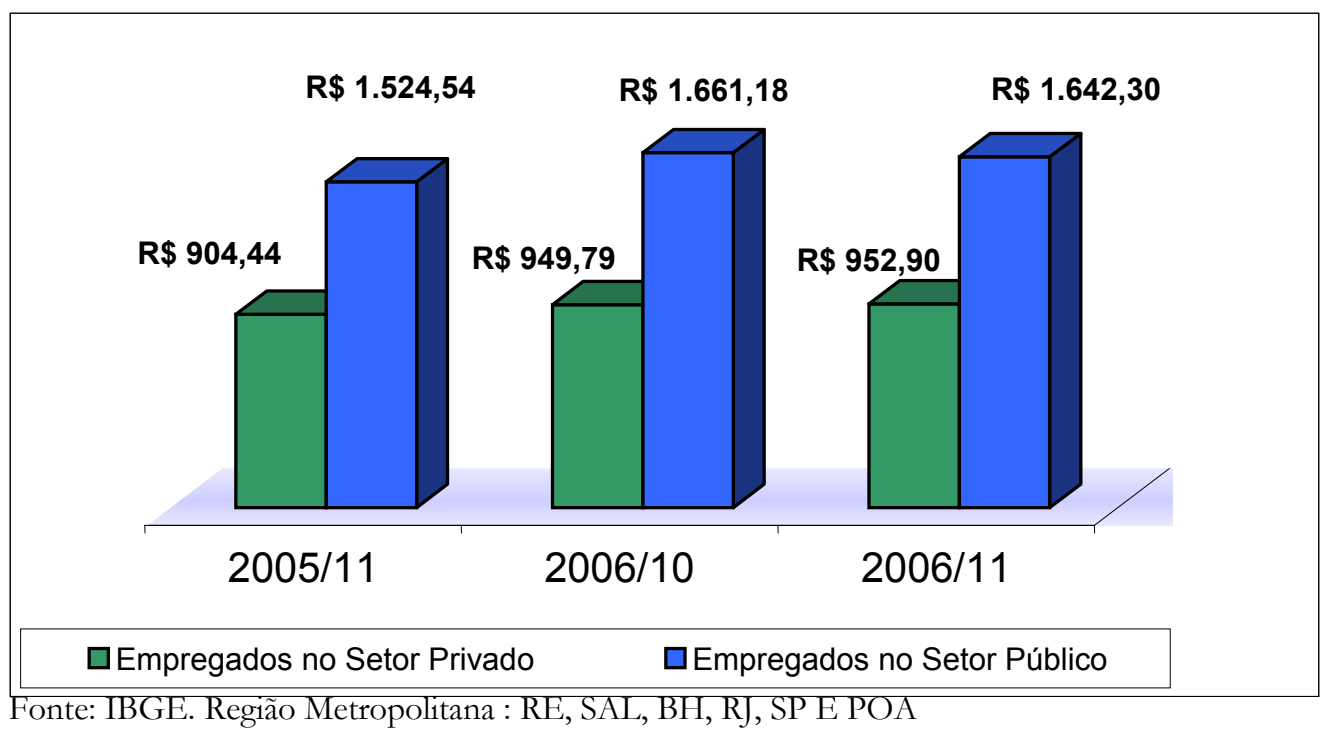

\section{Política Monetária}

A taxa de juros praticada na economia brasileira em novembro de 2006 foi de 13,25\%, abaixo do valor registrado de $14,17 \%$ no mês de setembro. Com uma inflação acumulada em 12 meses pelo IPCA de 3,02\% (ver tabela 1), calcula-se uma taxa de juros reais de $9,93 \%$ ao ano. Projetando a taxa de juros reais para o final do ano de 2007, pode-se 
argumentar que com a taxa de juros nominal esperada de $11,81 \%$ ao ano e esperando uma inflação do IPCA de 4,07\%, a taxa de juros reais estaria em 6,79\%. Fazendo o mesmo exercício, temos uma queda gradual e consistente da taxa de juros reais da economia brasileira, como demonstrado na tabela 5 .

Por exemplo, em 2010, de acordo com o Banco Central (Gerin), o mercado espera uma taxa de juros nominais em torno de 10,19\%. Como a inflação esperada para o final desse ano é de 4,28\% (ver tabela 2), a taxa de juros esperada (forward looking) é de 5,67\% ao ano.

Tabela 5. Taxa de juros (\%), câmbio (R\$/US\$) e Expectativas

\begin{tabular}{lcccccc}
\hline \multirow{2}{*}{ Descrição } & Novembro & \multicolumn{5}{c}{ Expectativas } \\
\cline { 3 - 7 } & & $\mathbf{2 0 0 6}$ & $\mathbf{2 0 0 7}$ & $\mathbf{2 0 0 8}$ & $\mathbf{2 0 0 9}$ & $\mathbf{2 0 1 0}$ \\
\hline Taxa de Juros Nominais (SELIC) & $13,25 \%$ & $13,25 \%$ & $11,81 \%$ & $11,16 \%$ & $10,51 \%$ & $10,19 \%$ \\
Taxa de Juros Reais & $9,93 \%$ & $9,84 \%$ & $6,79 \%$ & $6,62 \%$ & $6,00 \%$ & $5,67 \%$ \\
Taxa de Câmbio Nominal (R\$/US\$) & 2,15 & 2,15 & 2,24 & 2,37 & 2,47 & 2,54 \\
\hline Fonte: Banco Central do Brasil. Boletim Economia \& Tecnologia.
\end{tabular}

Fonte: Banco Central do Brasil. Boletim Economia \& Tecnologia.

Com relação à taxa de câmbio nominal, o mercado espera uma certa estabilidade para os anos de 2006 e 2007. Os ajustes nominais esperados do câmbio no longo prazo são irrelevantes para o equilíbrio do setor externo.

A condução da política monetária (leia-se: determinação da taxa de juros Selic) tem como objetivo principal no Brasil manter a estabilidade dos preços, determinada pelo IPCA. O regime de metas de inflação leva em consideração o desempenho de vários indicadores, variáveis e mercados e suas influências sobre os preços na economia. Neste sentido, pode-se destacar os seguintes pontos:

i. As expectativas de inflação para 2006 estão em 3,10\%, isto é, ancoradas com a meta de 4,5\% do IPCA com +/- 2 pontos percentuais;

ii. Os principais índice de preços estão apresentando um comportamento de convergência em suas variações anualizadas;

iii. A expectativa do mercado para o crescimento do PIB em 2006 está em 2,78\%;

iv. O setor da economia que apresenta maior expectativa de crescimento, tanto em 2006 quanto em 2007, é a indústria;

v. Os saldos da balança comercial e de serviços, atual e o esperado para o fim do ano, ainda são expressivos e fortes para manter ou reduzir o preço do dólar;

vi. A taxa de juros reais em novembro está em 9,93\% ao ano, prejudicando ainda o investimento privado. 
Gráfico 8. Taxa de Juros (Selic): janeiro de 2005 a dezembro de 2006

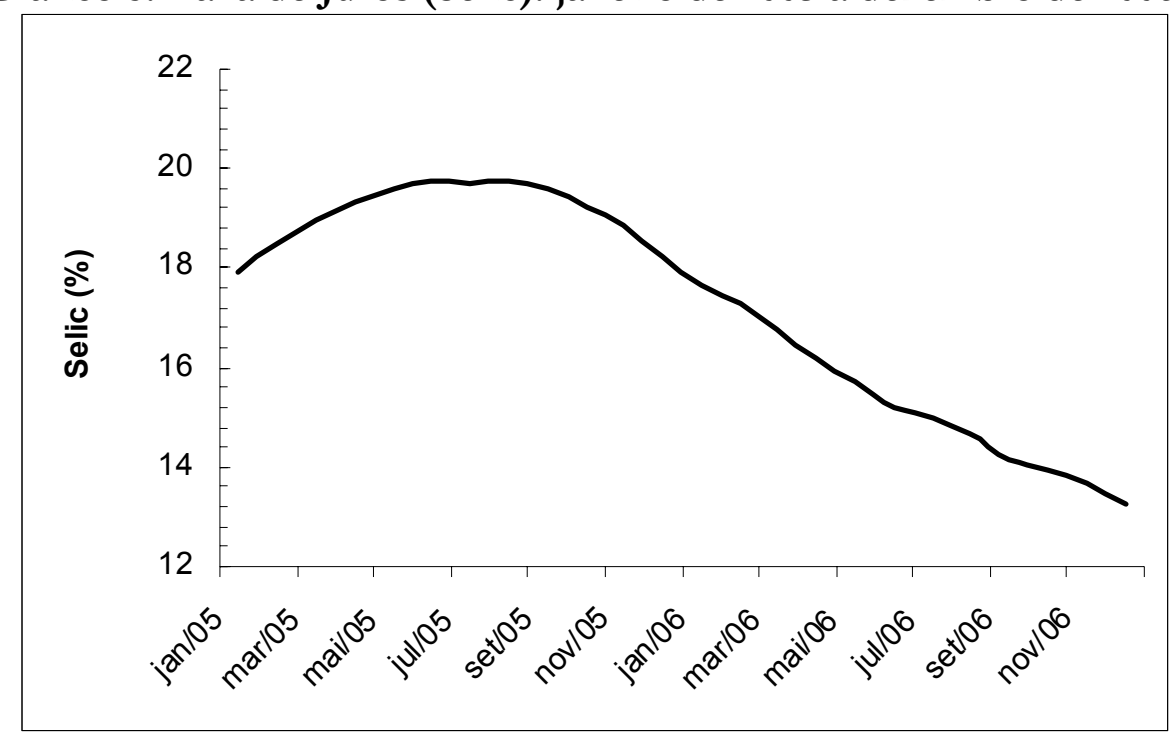

Fonte: Banco Central do Brasil

Com os resultados expostos acima, pode-se argumentar que não há nenhum fator conjuntural macroeconômico que possa pressionar significativamente o nível geral de preços da economia. Neste sentido, com a tendência de queda dos juros e de manutenção da estabilidade monetária, a taxa de juros pode continuar caindo, como destacado no gráfico 8. 